\title{
Bioactive Compounds in Bael Fruit Pulp Waste: Ultrasound-Assisted Extraction, Characterization, Modeling, and Optimization Approaches
}

\author{
Akshay Sonawane 1(D), Sumit Pathak ${ }^{1}$, Rama Chandra Pradhan 1,* (D) \\ 1 Department of Food Process Engineering, National Institute of Technology, Rourkela, India; akshayson22@gmail.com \\ (A.S.); jayantpathak28@gmail.com (S.P.); pradhanrc@nitrkl.ac.in (R.C.P.); \\ * Correspondence: pradhanrc@nitrkl.ac.in;
}

Scopus Author ID 57208038223

Received: 9.08.2020; Revised: 7.09.2020; Accepted: 9.09.2020; Published: 11.09.2020

\begin{abstract}
Bael fruit is an abundant source of bioactive compounds that have importance in the food and pharmaceutical industries. The process of extraction of the bael fruit juice produced a higher percentage of bael fruit pulp waste (BFPW) $(37.33 \%)$, which was recycled for the extraction of bioactive compounds. Thus the bioactive compounds like polyphenols, flavonoids, and carotenoids were extracted from BFPW by using the ultrasound-assisted extraction (UAE) technique. The modeling and optimization of the extraction process were carried out by using the experimental design of response surface methodology (RSM). The ethanol concentration of $51.22 \%$, ultrasound amplitude of $51.45 \%$, and ultrasound treatment time of 6.11 minutes were obtained to be an RSM optimized values of extraction process variables. The lower values of root mean squared error (RMSE) and mean absolute error (MAE) and higher values of coefficient of determination $\left(\mathrm{R}^{2}\right)$ indicated admissibility and acceptability of RSM. This extraction process of bioactive compounds has the potential to implement it on an industrial scale for the formulation of food additives and medicines.
\end{abstract}

Keywords: Bael fruit pulp waste; bioactive compounds; ultrasound-assisted extraction; response surface methodology (RSM).

(C) 2020 by the authors. This article is an open-access article distributed under the terms and conditions of the Creative Commons Attribution (CC BY) license (https://creativecommons.org/licenses/by/4.0/).

\section{Introduction}

Bael (Aegle marmelos $\mathrm{C}$.) is one of the most important indigenous medicinal fruit which grows in tropical and subtropical regions of Asia. Various parts of the bael tree, i.e., fruits, leaves, stem, roots, and bark, are found to be medicinally useful [1-4]. Among these parts, underutilized bael fruit possesses more nutritive values and can be processed to various products such as jam, jelly, juice, candy, squash, powder, capsules, toffee, wine, etc. The bael fruit is found to contain bioactive compounds, namely pectin, tannins, flavonoids, alkaloids, carotenoids, phenolic acid, terpenoids, and coumarins [5-7]. The presence of bioactive compounds imparts many health benefits in edible bael fruit and its products with antidiabetic activity, anticancer activity, antioxidant activity, antihistaminic activity, antiamoebic activity, antibacterial activity, antiulcer activity and, anti-inflammatory activity [8-10].

The processing of fruits and vegetables produces industrial solid waste such as rind, skin, seed, core, pod, pomace, peels, etc. which are the potential source of bioactive and nutraceutical compounds. This solid waste has grabbed the attention of researches for the valorization or extraction of the essential compounds [11-13]. The recycling or reuse of 
industrial food solid waste for the extraction of essential compounds is found to be useful as it helps to eradicate environmental pollution [14,15]. During the processing of bael fruit products, many waste material, i.e., hard rind or peel, fibers, seeds, etc. are obtained. They also contain bioactive and pharmaceutical compounds [16]. The delicious 'sherbat' or bael fruit juice has been reported to possess tonic, laxative, restorative, and digestive properties and can be used for preparing jam, jelly, wine, and squash [17-20]. Therefore, Singh et al. (2013) have commercialized the bael fruit into nutritious juice by using enzymatic hydrolysis of bael fruit pulp. The cake of fiber or retentate has been obtained in muslin cloth after the mechanical expression of juice. This cake of fibers or retentate is considered a byproduct of solid waste of the bael fruit juice extraction process and termed as a bael fruit pulp waste (BFPW) [7]. Various bioactive and pharmaceutical compounds can be recovered from BFPW as bael fruit pulp is an abundant source of many bioactive and pharmaceutical compounds such as $\beta$-carotene, marmelosin, luvangetin, aurapten, psoralen, marmelide, riboflavin, flavonols, flavonoid glycosides, leucoanthocyanins, umbelliferone, and anthocyanins [6,21]. These compounds cannot be available easily in any other fruits and have particular importance in the pharmacy for preparing the food additives and medicines. The extracted bioactive and pharmaceutical compounds also act as medicinal additives, which can be incorporated in some medicines $[7,22,23]$. So the BFPW can potentially be used for the extraction of bioactive and pharmaceutical compounds.

Several methods of bioactive and pharmaceutical extraction have been implemented in medicinal and food industries from plant material or food solid waste. These methods include solid-solvent extraction, supercritical fluid extraction, accelerated solvent extraction, soxhlet extraction, enzyme-assisted extraction, microwave-assisted extraction, ultrasonic-assisted, and ultrasound-assisted extraction (UAE) [24-32]. The conventional methods of extraction, such as heating, boiling of refluxing hydrolyze, degrade, ionize, and oxidize the targeted bioactive compounds leading to lower extraction efficiency [25]. The ultrasound-assisted extraction of bioactive compounds can be deemed as a novel, environment-friendly, low-cost technique with higher extraction efficiency [31,33,34]. The ultrasound-assisted extraction is a non-thermal technique that allows the more retention of bioactive compounds during extraction. The ultrasound cavitation produces shear stress in the cell wall. It results in the mechanical breakdown of cell walls, which allows more diffusion rate or material transfer across the cell wall $[35,28,36,37]$. The ultrasound-assisted extraction (UAE) technique has been reported in many plants, food, and waste materials for the extraction of bioactive or essential compounds. The previous works on the UAE of essential compounds have been shown in Table 1.

The bioactive compounds present in fruits mainly comprise of polyphenols, flavonoids, and carotenoids [53-55,45]. The polyphenols, which are categorized as phenolic acids, stilbenes, flavonoids, and lignans, exhibit the antioxidant activity and can be useful for heart diseases. Flavonoids include flavanols, anthocyanidins, isoflavones, flavones, flavanones, etc., which can prevent oxidation, coronary heart disease, and cancer of membrane lipids [56,57]. The lutin, $\beta$-carotene, zeaxanthin, $\alpha$-carotene, $\beta$-cryptoxanthin, etc. are included in carotenoid, which decreases the risk of cancer, chronic diseases, and other degenerative [58].

This paper includes the process of ultrasound-assisted extraction (UAE) of bioactive compounds from the bael fruit pulp waste (BFPW). The article also covers the modeling and optimization of the extraction process by using response surface methodology (RSM) for its Commercialization on an industrial scale. 
Table 1. Extraction of bioactive compounds by using ultrasound treatment.

\begin{tabular}{|c|c|c|}
\hline Materials & Analytes & References \\
\hline Pomegranate wastes & Carotenoids & {$[38]$} \\
\hline Peaches and Pumpkins & Phenolic compounds & [39] \\
\hline Haskap berries (Lonicera caerulea L.) & Anthocyanins & {$[40]$} \\
\hline Spinach extract & Polyphenols & [41] \\
\hline Grapefruit (Citrus paradisi L.) solid wastes & Flavonoids & [42] \\
\hline Carrot (Daucus carota Linn) & Carotenoids & [43] \\
\hline Marjoram (Origanum majorana L.) & Antioxidant compounds & {$[44]$} \\
\hline Inula helenium & Flavonoids & [45] \\
\hline Mangifera pajang Kosterm. peels & Phenolic compounds & {$[46]$} \\
\hline Prunella vulgaris $\mathrm{L}$. & Flavonoids & [47] \\
\hline Orange (Citrus sinensis L.) peel & Polyphenols (flavanone glycosides) & {$[31]$} \\
\hline Du Zhong Ye (Folium eucommiae) & Flavonoids & {$[48]$} \\
\hline Penggan $($ C. reticulate $)$ & Total phenolic content & [49] \\
\hline Satsuma mandarin (C. unshiu Marc) & Flavanone glycosides and phenolic acids & {$[50]$} \\
\hline Pomegranate (Punica granatum L.) peel & Phenolic compounds & [51] \\
\hline Almond extract & Phenolics, tannins, anthocyanin, and total flavonoids & {$[52]$} \\
\hline
\end{tabular}

\section{Materials and Methods}

\subsection{Process for bael fruit juice extraction and its byproduct.}

The Kagzi variety of Bael fruits were harvested from trees, which are located on the campus of the National Institute of Technology, Rourkela (Location: $22.2604^{\circ} \mathrm{N}, 84.8536^{\circ} \mathrm{E}$ ). Fruits were stored in a deep freezer at $-20 \pm 2{ }^{\circ} \mathrm{C}$. The ripen fruits (orange-yellowish color) were broken by using the hammer, and pulp was scooped along with seeds and fibers. The scooped pulp was passed through an IC30 sieve to separate the seeds and large fibers from the pulp. The water was added to the fined texture sieved pulp in the proportion of 2:1 (water: pulp) to obtain bael fruit juice easily. The bael fruit juice was extracted enzymatically by using pectinase enzyme (EC-232-885-6) (activity: 8000-12000 units/g, commercial name: Himedia, Mumbai, India) of $0.20 \mathrm{mg}$ per $100 \mathrm{~g}$ of pulp at $45^{\circ} \mathrm{C}$ for 6 hours and then passing it through muslin cloth with the application of mechanical pressure. The byproduct of the bael fruit juice extraction process, i.e., cake or retentate or bael fruit pulp waste (BFPW), remained in the muslin cloth after extraction of juice. The collected BFPW was used as a primary sample for the extraction of bioactive compounds. The mass balancing of bael fruit juice and its byproduct, i.e., BFPW, was done for the calculation of percentage waste of bael fruit pulp. The moisture content of sieved bael fruit pulp and BFPW was determined gravimetrically at $105 \pm 2{ }^{\circ} \mathrm{C}$ for 24 hours [59].

\subsection{Extraction and separation of bioactive compounds.}

The homogeneous mixture of $50 \mathrm{~mL}$ of ethanol and $10 \mathrm{~g}$ of BFPW was allowed for ultrasound treatment. The solvent volume to sample ratio was kept constant throughout the experiment. A probe-type ultra-sonicator (Model: Q700 Sonicator, Qsonica Sonicator, USA) with a maximum power rating of 700 Watt and a frequency of $20 \mathrm{kHz}$ was used for ultrasound treatment. The power of ultrasound was controlled by its amplitude, which ranges from 1 to $100 \%$. A standard probe of $1 / 2$ " diameter was used to generate the ultrasounds with the pulseon time of 10 seconds and a pulse-off time of 10 seconds. The probe was dipped 1.5 times the diameter of the glass beaker, which contains the sample. The temperature of BFPW was maintained below $45^{\circ} \mathrm{C}$ during ultrasound treatment $[60,61]$. After ultrasound treatment, the sample was centrifuged at $12000 \mathrm{rpm}$ for 5 minutes at $25^{\circ} \mathrm{C}$ in decanter centrifuge (Model: Sigma 2-16KL, Sigma Laborzentrifugen $\mathrm{GmbH}$, Germany) to separate the solids of BFPW 
from the extract of bioactive compounds. The separation of ethanol from the extract was carried out in a rotary vacuum evaporator at 130 mbar pressure and $45^{\circ} \mathrm{C}$ for 30 minutes with a speed of $150 \mathrm{rpm}[31,47]$. The ethanol-free extract of bioactive compounds was stored at $-20 \pm 2{ }^{\circ} \mathrm{C}$ for further analysis. The conventional solid-liquid extraction method of the bioactive compound was performed to compare with the UAE [42]. The process of extraction of bioactive compounds from BFPW is shown in Figure 1.

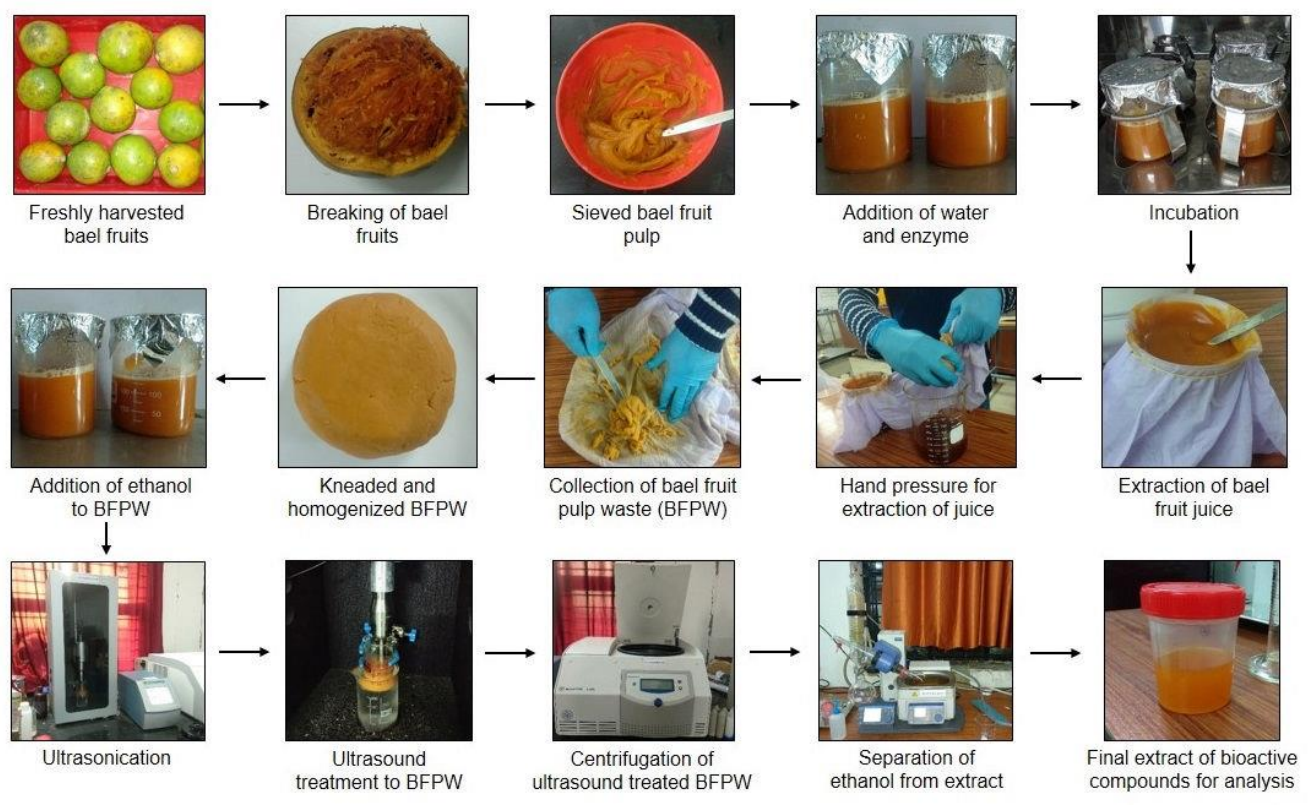

Figure 1. Process for ultrasound-assisted extraction of bioactive compounds.

\subsection{Experimental design.}

Three operational variables, i.e., ethanol concentration (X1), ultrasound amplitude (X2), and ultrasound treatment or process time (X3), were considered for the extraction of bioactive compounds. The lower (-1) and upper (+1) limits of operational variables were set by performing primary experiments. The coded values, i.e., -1 and +1 , correspond to the lower and upper limits of actual values, respectively. The ethanol concentration was varied from 30 $(-1)$ to $90(+1) \%(\% \mathrm{v} / \mathrm{v})$ by dilution with distilled water. The ultrasound amplitude was varied across the range from $40(-1)$ to $80(+1) \%$. The Ultrasound treatment time was set from $4(-1)$ to $10(+1)$ minutes. The . Box-Behnken design of response surface methodology (RSM) was carried out to get the total runs (experimental trials) of different combinations in Design-Expert software 11.0. Box-Behnken design of three variables gives 17 experimental trials.

\subsection{Characterization of extracted bioactive compounds.}

After the separation of ethanol from the extracts of bioactive compounds, the remaining extracts were made up to the volume of $50 \mathrm{~mL}$ with distilled water to equalize their volumes for the determination and comparison of extracted bioactive compounds. The characterization comprised the determination of total phenol content, total flavonoids, total carotenoids, and DPPH scavenging activity.

Total phenol content (TPC) was measured spectrophotometrically by using the FolinCiocalteu assay, which was described by Singleton and Rossi (1965) with slight modifications [62]. The Folin-Ciocalteu reagent was diluted 10-fold with distilled water. The extract of 125 $\mu \mathrm{L}$ was then added to $1.8 \mathrm{~mL}$ diluted Folin-Ciocalteu reagent. The prepared solution was 
allowed to stand for 5 minutes. The solution of $15 \%$ sodium carbonate was then added to the prepared solution. The absorbance was measured at $765 \mathrm{~nm}$ after 90 minutes of incubation time at room temperature. The TPC was expressed in $\mathrm{mg}$ of gallic acid equivalents per $\mathrm{mL}$ of extract after comparing the absorbance with the standard graph of gallic acid with the equation: $\mathrm{y}=$ $1.4584 \mathrm{x}+0.0629\left(\mathrm{R}^{2}=0.9932\right)$.

Total flavonoids (TF) were determined as per the procedure described by Woisky and Salatino (1998) with slight modification [63]. The extract of $0.5 \mathrm{~mL}$ was added to $0.5 \mathrm{~mL}$ of $2 \% \mathrm{AlCl}_{3}$ and $2.5 \mathrm{~mL}$ of $99 \%$ methanol. After incubation for $15 \mathrm{~min}$ at room temperature, the absorbance was measured by UV-vis Spectrophotometer (Model: AU 2701, Systronics, India) at $420 \mathrm{~nm}$. The TF was expressed in $\mu \mathrm{m}$ of rutin equivalents per $\mathrm{mL}$ of extract as rutin was used as the standard for obtaining the curve of the equation: $y=1.4784 x+0.0471\left(R^{2}=\right.$ 0.9882).

Total carotenoid (TC) was determined according to the method of Hess et al. (1991) with some modifications [64]. The extract of $300 \mu \mathrm{L}$ was added to $300 \mu \mathrm{L}$ of water and $600 \mu \mathrm{L}$ of ethanol to make an ethanolic solution. Then it was extracted to $600 \mu \mathrm{L}$ of $\mathrm{n}$-hexane. The absorbance was measured at $450 \mathrm{~nm}$ in UV-vis Spectrophotometer (Model: AU 2701, Systronics, India). The results were expressed in $\mu \mathrm{g}$ of $\beta$-carotene equivalents per $\mathrm{mL}$ of extract. The standard curve of $\beta$-carotene has shown the equation: $y=2.0051 x+0.0693$ with $\mathrm{R}^{2}$ of 0.9835 .

The method of Liu et al. (2009) was implemented for the determination of DPPH (2,2diphenyl-1-picrylhydrazyl) scavenging activity with some modifications [65]. The DPPH solution was prepared daily with a concentration of $0.4 \mathrm{mmol} / \mathrm{L}$ of DPPH in $95 \%$ ethanol. The extract of bioactive compounds was diluted with distilled water at a dose of $1 \mathrm{~mL}$ of extract per $4 \mathrm{~mL}$ of water. The $2 \mathrm{~mL}$ diluted extract was added to $2 \mathrm{~mL}$ of DPPH solution and $2 \mathrm{~mL}$ of $95 \%$ ethanol each. Then the mixtures were shaken vigorously and allowed for 30 minutes of incubation time at ambient room temperature in a dark place. The absorbance was taken at 517 $\mathrm{nm}$ against the blank. The DPPH scavenging activity was calculated by the following equation.

DPPH scavenging activity $(\%)=\left[1-\frac{\left(A_{i}-A_{j}\right)}{A_{c}}\right] \times 100$

where $\mathrm{Ac}=2 \mathrm{~mL}$ of DPPH solution $+2 \mathrm{~mL}$ of $95 \%$ ethanol, $\mathrm{Ai}=2 \mathrm{~mL}$ of diluted extract +2 $\mathrm{mL}$ of DPPH solution and $\mathrm{Aj}=2 \mathrm{~mL}$ of diluted extract $+2 \mathrm{~mL}$ of $95 \%$ ethanol.

The results of TPC $(\mathrm{mg})$, TF $(\mathrm{mg})$, and TC $(\mu \mathrm{g})$ were determined per $\mathrm{mL}$ of the extract of bioactive compounds from their respective standard curve equations and finally represented per $100 \mathrm{~mL}$ of the extract of bioactive compounds. All analyses were performed in triplicates for every run, further taking the mean values along with the standard deviation.

\subsection{RSM model and optimizations.}

The responses, namely TPC (Y1), TF (Y2), TC (Y3), and DPPH scavenging activity (Y4), were taken into account in RSM as the main targeted parameters. The effect of variables such as ethanol concentration (X1), ultrasound amplitude (X2), and ultrasound treatment time (X3) on responses was performed and studied by developing different mathematical regression equations, which may contain linear, quadratic, and interaction terms. The second-order polynomial regression equation of RSM was used to express the responses as a function of variables, as shown in equation $2[46,66]$. 
$\mathrm{Y}=\beta_{0}+\sum \mathrm{b}_{1} \mathrm{X}_{1}+\sum \mathrm{b}_{2} \mathrm{X}_{2}+\sum \mathrm{b}_{3} \mathrm{X}_{3}+\sum \mathrm{b}_{12} \mathrm{X}_{1} \mathrm{X}_{2}+\sum \mathrm{b}_{13} \mathrm{X}_{1} \mathrm{X}_{3}+\sum \mathrm{b}_{23} \mathrm{X}_{2} \mathrm{X}_{3}+$ $\sum \mathrm{b}_{1}{ }^{2} \mathrm{X}_{1}{ }^{2}+\sum \mathrm{b}_{2}{ }^{2} \mathrm{X}_{2}{ }^{2}+\sum \mathrm{b}_{3}{ }^{2} \mathrm{X}_{3}{ }^{2}$

where $\mathrm{Y}$ is predicted response, $\mathrm{b}_{1}, \mathrm{~b}_{2}$, and $\mathrm{b}_{3}$ are the linear coefficients, $\mathrm{b}_{12}, \mathrm{~b}_{13}$, and $\mathrm{b}_{23}$ are the interaction coefficients, whereas $b_{12}, b_{22}$, and $b_{32}$ are the quadratic coefficients. The RSM models or equations of responses were validated by using an analysis of variance (ANOVA) of Design-Expert software 11.0. Three-dimensional plots (response surfaces) were obtained by using RSM polynomial equations to study the effect of variables on responses [67].

All four responses, i.e., TPC, TF, TC, and DPPH scavenging activity, were assigned as maximum parameters to obtain the optimized values of variables for the extraction of bioactive compounds. The RSM optimization was carried out in the numeric optimization tool of DesignExpert software 11.0. The corresponding values of responses were determined from the optimized values of variables for RSM optimization [39].

\subsection{Validation of the RSM model.}

The coefficient of determination $\left(\mathrm{R}^{2}\right)$, mean absolute error (MAE), and root mean squared error (RMSE) was calculated for the validation of developed RSM models or equations. The formulae of $\mathrm{R}^{2}$, MAE, and RMSE are given below $[68,69]$.

$$
\begin{aligned}
& \mathrm{R}^{2}=\left(\sum_{\mathrm{i}=1}^{\mathrm{n}}\left(\mathrm{Yi}_{\text {pre }}-\mathrm{Yi}_{\text {obs }}\right)^{2}\right) / \sum_{\mathrm{i}=1}^{\mathrm{n}}\left(\mathrm{Yi}_{\text {pre }}-\overline{\mathrm{Y}}\right)^{2} \\
& \text { MAE }=\frac{1}{\mathrm{n}} \sum_{\mathrm{i}=1}^{\mathrm{n}}\left|\left(\mathrm{Yi}_{\text {obs }}-\mathrm{Yi}_{\text {pre }}\right)\right| \\
& \text { RMSE }=\sqrt{\frac{1}{\mathrm{n}} \sum_{\mathrm{i}=1}^{\mathrm{n}}\left(\mathrm{Yi}_{\text {obs }}-\mathrm{Yi}_{\text {pre }}\right)^{2}}
\end{aligned}
$$

where $\mathrm{Yi}$ obs is an observed value of the response, $\mathrm{Yi}$ pre is $\mathrm{RSM}$ predicted value of the response, $\overline{\mathrm{Y}}$ is the average value of the observed responses, and $\mathrm{n}$ is the number of data points for a single response.

\section{Results and Discussion}

\subsection{Mass balancing of the bael fruit juice extraction process.}

The moisture content of sieved bael fruit pulp was found out to be $68.25 \pm 1.25 \%$ (wet basis). The mass balancing was done on the basis of weights. The sieved bael fruit pulp of 3 $\mathrm{kg}$ and $6 \mathrm{~kg}$ of water (1:2 ratio of pulp to water) were mixed thoroughly and then allowed for enzymatic extraction of juice. The clear bael juice of 7.74 kilograms (juice yield of 58\%) was extracted from $9 \mathrm{~kg}$ homogeneous mixture of sieved pulp and water with handling losses of $0.14 \mathrm{~kg}$. The bael fruit pulp waste (BFPW) was recovered from the muslin cloth after extraction of juice and weighed to be $1.12 \mathrm{~kg}$. The percentage of waste obtained from sieved bael fruit pulp during the juice extraction process was determined to be $37.33 \%$. The presence of fibers contributes to the complex nature of bael fruit pulp, which produces a higher percentage of waste, i.e., BFPW, along with bioactive compounds [70]. The BFPW was found to have a moisture content of $62.45 \pm 1.22 \%$ on the wet basis, and this confirmed the higher water holding capacity of fibers (cellulose), which are present numerously in the bael fruit pulp [71]. 


\subsection{Conventional extraction versus $U A E$.}

The bioactive compounds were extracted by the conventional method of solid-liquid extraction from BFPW. The conventional solid-liquid extraction methods involved the addition of water to the BFPW, and heating of water added BFPW for some time. The water-added sample of BFPW was heated to $60^{\circ} \mathrm{C}$ for 30 minutes [42]. The conventional extraction of bioactive compounds has shown the values of TPC, TF, TC, and DPPH scavenging activity as $37.25 \pm 1.45 \mathrm{mg} / 100 \mathrm{~mL}, 15.78 \pm 1.04 \mathrm{mg} / 100 \mathrm{~mL}, 2.54 \pm 0.96 \mu \mathrm{g} / 100 \mathrm{~mL}$, and $41.47 \pm 1.27 \%$ respectively. These values were found to be effectively lower than the ultrasound-assisted extracted bioactive compounds. The superiority of UAE over conventional extraction has been reported in many food types of research $[31,42,72,41,73,39]$. The conventional solid-liquid extraction process gives less extraction efficiency of bioactive compounds as it comprehends higher temperature and extraction time, which degrade or denature the polyphenols, flavonoids, and carotenoids. Consequently, it reduces overall antioxidant activity or free radical scavenging activity [74-78,38]. In contrast, ultrasound-assisted treatment gives higher extraction efficiency of bioactive compounds, as it is a non-thermal processing technology that works on the principle of cavitation $[47,72,79,80,73,45,44]$. Many pharmaceutical industries, therefore, have been using ultrasound-assisted extraction technique by coupling with other non-thermal extraction techniques for obtaining the higher extraction efficiency of bioactive compounds.

\subsection{RSM analysis.}

The Box-Behnken design of response surface methodology (RSM) has developed the quadratic equations (models) for every response. The predicted values of responses, namely TPC, TF, TC, and DPPH scavenging activity, were determined by the RSM quadratic equation, which was in the form of equation 2. The observed values with their standard deviation and RSM predicted values of responses are given in Table 2. The developed models of quadratic equations have given the values of regression coefficients. The regression coefficients of linear, interaction, and quadratic terms with their significance are shown in Table 3. The significance of quadratic models, as well as lack of fit, were determined by ANOVA. F-values of 57.61, 39.55, 29.99, and 40.25 for TPC, TF, TC, and DPPH scavenging activity respectively have indicated that the developed models are significant $(\mathrm{p}<0.0001)$.

The lack of fit for all models was found out to be insignificant as F-values of lack of fit were $2.45,1.92,0.5267$, and 3.45 for TPC, TF, TC, and DPPH scavenging activity, respectively. The insignificancy of a lack of fit is desirable and acceptable for the model to fit $[60,81]$. The coefficient of determination $\left(\mathrm{R}^{2}\right)$ value should be higher than 0.80 for the best fit model [82]. The $\mathrm{R}^{2}$ values of all developed models were determined to be more than 0.80 , as mentioned in Table 3. This indicates that the developed RSM models are the best fit models. The difference of less than 0.20 agreed to the reasonable relation between adjusted and predicted $\mathrm{R}^{2}$ for all models. The values of mean absolute error (MAE) and root mean squared error (RMSE) are shown in Table 3. These values were found out to be within the acceptable limits corresponding to their observed and predicted values of responses $[83,18]$. 


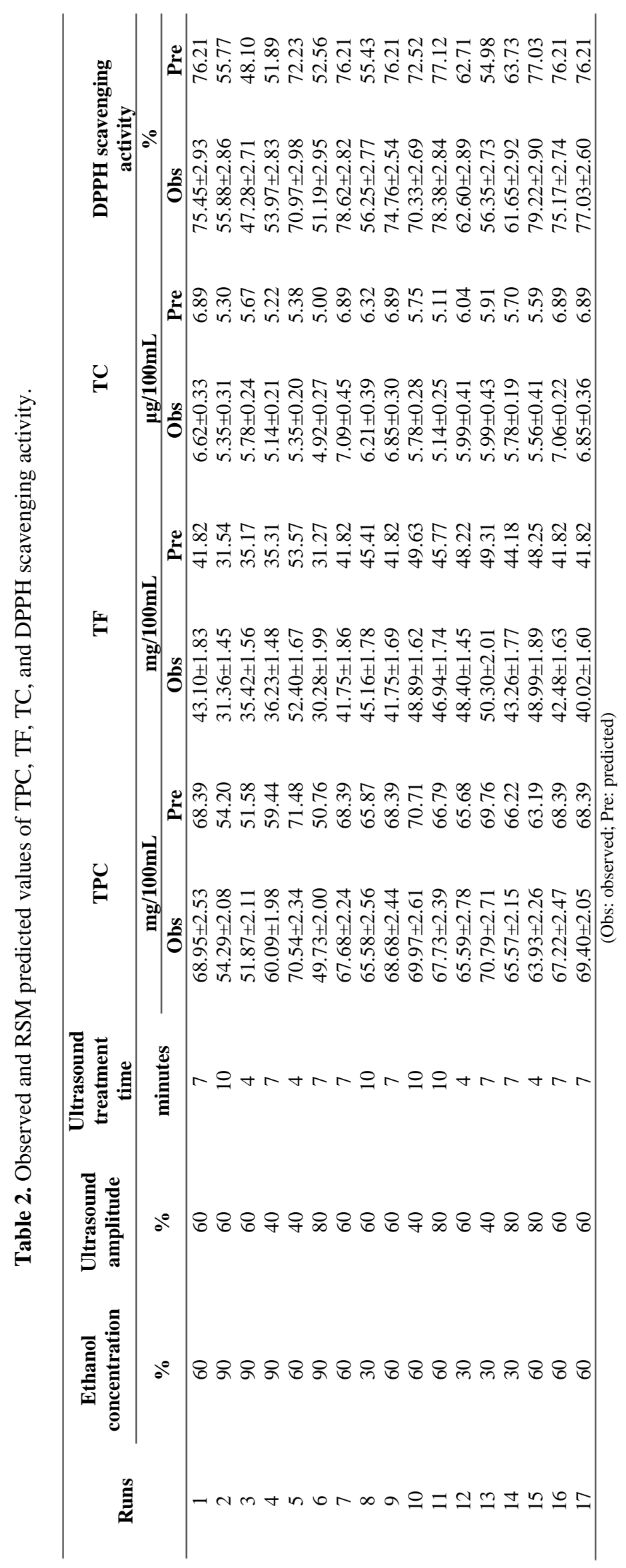


Table 3. Regression coefficients of the RSM model.

\begin{tabular}{l|l|l|l|l} 
Regression coefficients & TPC & TF & TC & DPPH scavenging activity \\
\hline$\beta_{0}$ & 68.39 & 41.82 & 6.89 & 76.21 \\
\hline $\mathrm{b}_{1}$ & $-6.44^{* * *}$ & $-6.73^{* * *}$ & $-0.35^{* * *}$ & $-3.57^{* *}$ \\
\hline $\mathrm{b}_{2}$ & $-3.05^{* * *}$ & $-2.29^{* *}$ & $-0.11^{*}$ & $2.35^{*}$ \\
\hline $\mathrm{b}_{3}$ & $0.71^{*}$ & $-1.61^{* *}$ & -0.03 & $0.10^{*}$ \\
\hline $\mathrm{b}_{1} \mathrm{~b}_{2}$ & $-1.29^{*}$ & 0.27 & 0.00 & -2.02 \\
\hline $\mathrm{b}_{1} \mathrm{~b}_{3}$ & 0.61 & -0.21 & $-0.16^{*}$ & $3.74^{* *}$ \\
\hline $\mathrm{b}_{2} \mathrm{~b}_{3}$ & 1.09 & 0.37 & $-0.21^{*}$ & -0.05 \\
\hline $\mathrm{b}_{1}{ }^{2}$ & $-7.78^{* * *}$ & $-5.51^{* * *}$ & $-0.53^{* * *}$ & $-19.82^{* * *}$ \\
\hline $\mathrm{b}_{2}{ }^{2}$ & 0.93 & $3.71^{* * *}$ & $-0.91^{* * *}$ & -0.60 \\
\hline $\mathrm{b}_{3}{ }^{2}$ & $-1.28^{*}$ & $3.78^{* * *}$ & $-0.53^{* * *}$ & -0.88 \\
\hline $\mathrm{R}^{2}$ & 0.99 & 0.98 & 0.97 & 0.98 \\
\hline Adjusted $\mathrm{R}^{2}$ & 0.97 & 0.96 & 0.94 & 0.96 \\
\hline Predicted $\mathrm{R}^{2}$ & 0.85 & 0.81 & 0.86 & 0.77 \\
\hline MAE & 0.6600 & 0.7282 & 0.0870 & 1.30 \\
\hline RMSE & 0.7398 & 0.8744 & 0.1094 & 1.47
\end{tabular}

\subsection{Effect of variables on the extraction of bioactive compounds.}

The effect of operational variables, i.e., ethanol concentration, ultrasound amplitude, and ultrasound treatment time on the TPC, TF, TC, and DPPH scavenging activity, was studied by the responses surfaces (three-dimensional graphs) which were obtained from the equations of developed models. The operational variables showed a greater effect on the extraction process of bioactive compounds because all models were significant $(p>.05)$ as per the results of ANOVA [84].

The total phenol content (TPC) ranged from 49.73 to $70.79 \mathrm{mg}$ gallic acid equivalent per $100 \mathrm{~mL}$ of extract for the extraction process. Figure 2 (i-a) shows the highest TPC at a lower amplitude and in the middle range of ethanol concentration. The ultrasound treatment time has shown a negligible effect on the extraction of polyphenols (Figure 2 (i-b and c)). The ethanol concentration and ultrasound amplitude had a negative significant linear impact on TPC; in contrast, the ultrasound treatment time had a positive significant linear effect on TPC. Higher amplitude may increase the cavitation, which can cause the degradation of polyphenols [39]. The ethanol enhances the diffusivity and solubility of polyphenols by lowering the dielectric constant of BFPW. The higher concentration of ethanol makes the diffusion very difficult by denaturing the protein cell wall [85]. Similar kinds of the effect of ethanol concentration on TPC were obtained by Hossain et al. (2012), Prasad et al. (2011), and Altemimi et al. (2015), which showed a similar trend of TPC extraction for ultrasound treatment.

The total flavonoids (TF) were found to be ranged from 30.28 to $52.48 \mathrm{mg}$ rutin equivalent per $100 \mathrm{~mL}$ of extract. Figure 2 (ii-a) represents the higher extraction of flavonoids in the middle range of ethanol concentration and at either lower or higher amplitude of ultrasound treatment. Similarly, in Figure 2 (ii-b and c), the extraction process has given the highest flavonoid content, either lower or a higher range of ultrasound treatment time. The ethanol concentration, ultrasound amplitude, and ultrasound treatment time have shown a negative significant linear effect on the extracted TF. The moderate concentration of ethanol for higher extraction of TF may indicate the medium polar components present in the BFPW, whereas middle ranges of ultrasound amplitude and treatment time may attain saturation condition for denaturation of flavonoids, which is not favorable for higher extraction of flavonoids [74]. The results of TF supports the findings of Garcia-Castello et al. (2015), Wang et al. (2012) and Altemimi et al. (2015). 
The total carotenoids (TC) is the major targeted bioactive compounds for UAE. TC had an extraction range from 7.09 to $4.92 \mu \mathrm{g} \beta$-carotene equivalents per $100 \mathrm{~mL}$ of extract. The middle ranges of ethanol concentration, ultrasound amplitude, and ultrasound treatment time have given the highest content of extracted carotenoids, as shown in Figure 3 (iii). The negative significant linear effect has been shown by ethanol concentration and ultrasound amplitude on the TC, whereas ultrasound treatment time had a linear non-significant impact on TC. The results of ethanol concentration on TC are in agreement with the results of Goula et al. (2017).

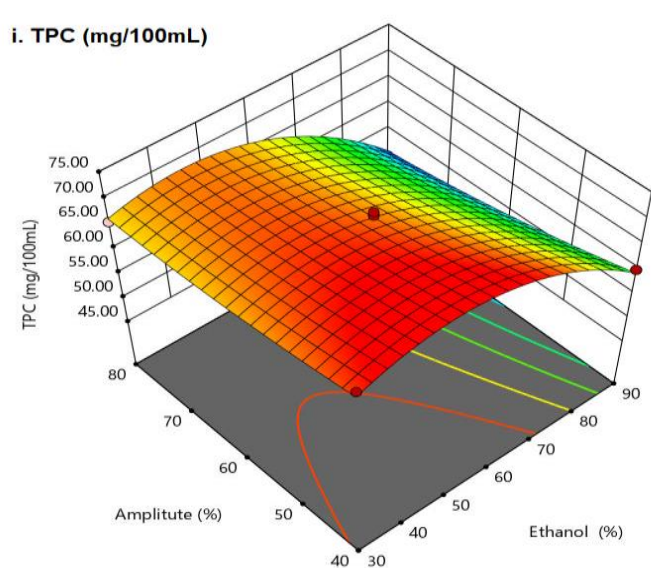

(a)

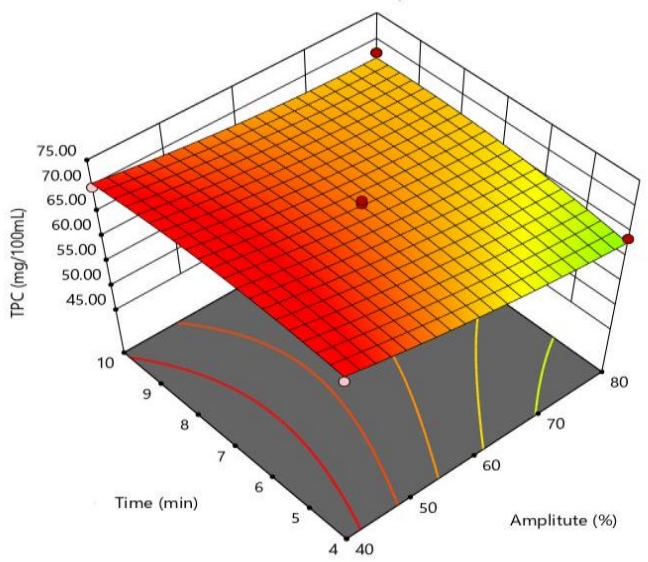

(b)

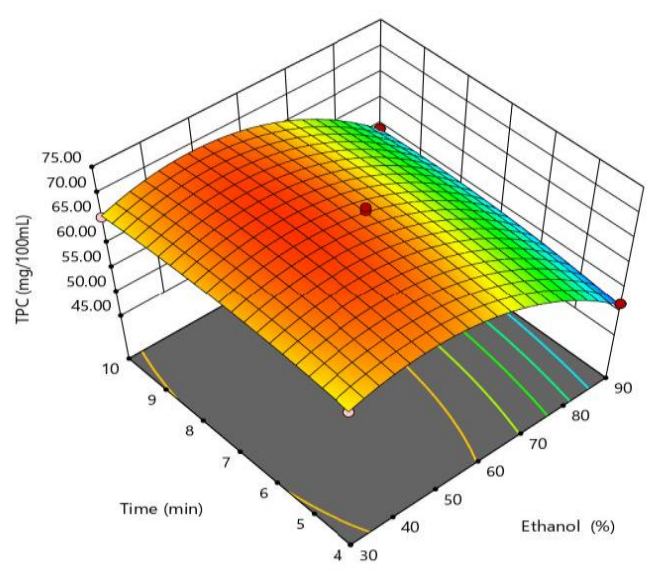

(c)

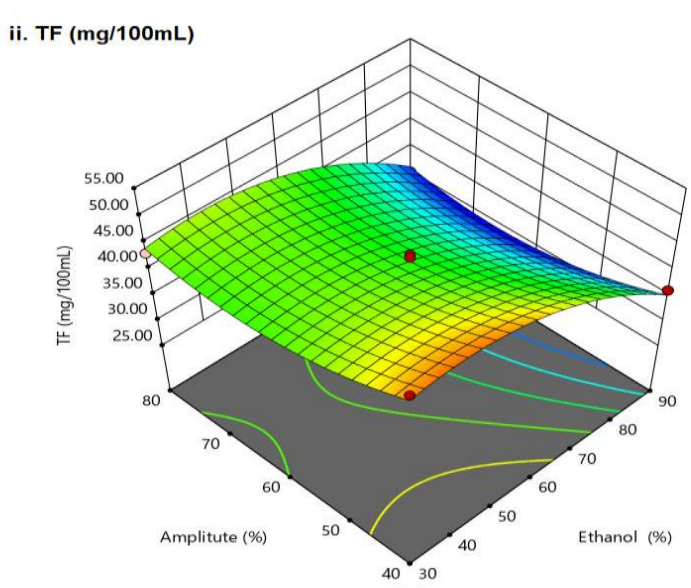

(a)

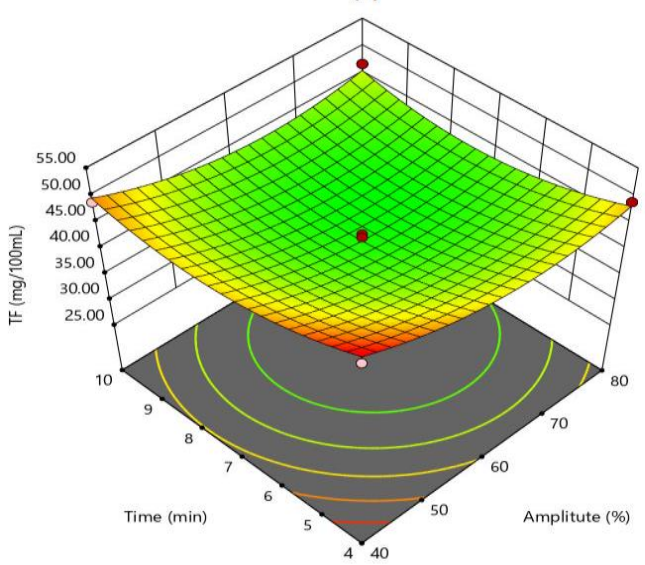

(b)

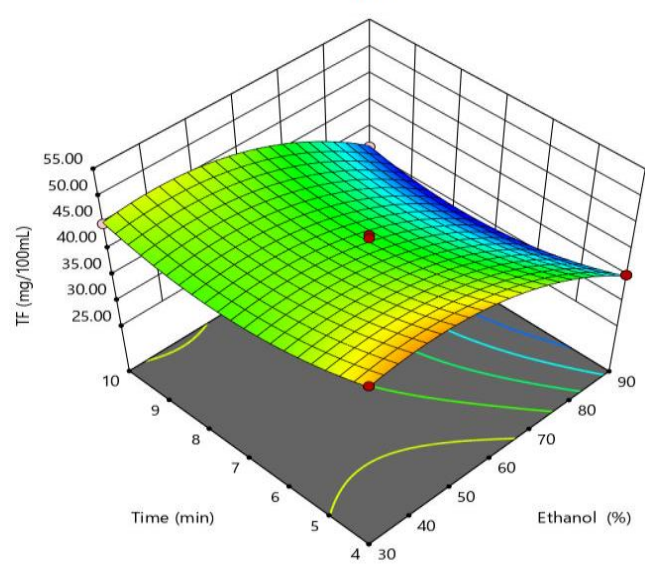

(c)

Figure 2. Response surfaces of TPC and TF.

The DPPH (2,2-diphenyl-1-picrylhydrazyl) scavenging activity represents the overall antioxidant activity of extracted bioactive compounds. The ethanol concentration between 50 to $70 \%$ has given the highest DPPH activity, as shown in Figure 3 (iv-a). From Figure 3 (iv-b), 
the DPPH scavenging activity is increasing with an increase in ultrasound amplitude. The ultrasound treatment time appeared to have very negligible effects on DPPH scavenging activity, as shown in Figure 3 (iv-b and c). The ethanol concentration showed a significant negative impact, whereas ultrasound amplitude and ultrasound treatment time had a significant positive effect on DPPH scavenging activity. The DPPH scavenging activity always may not be directly proportional to total phenol content as scavenging activity is shown by the many compounds such as polyphenols, carotenoids, flavonoids, polysaccharides, etc. [46]. The results of DPPH scavenging activity were found to similar to the outcomes of Altemimi et al. (2016), Goula et al. (2017), and Altemimi et al. (2015).

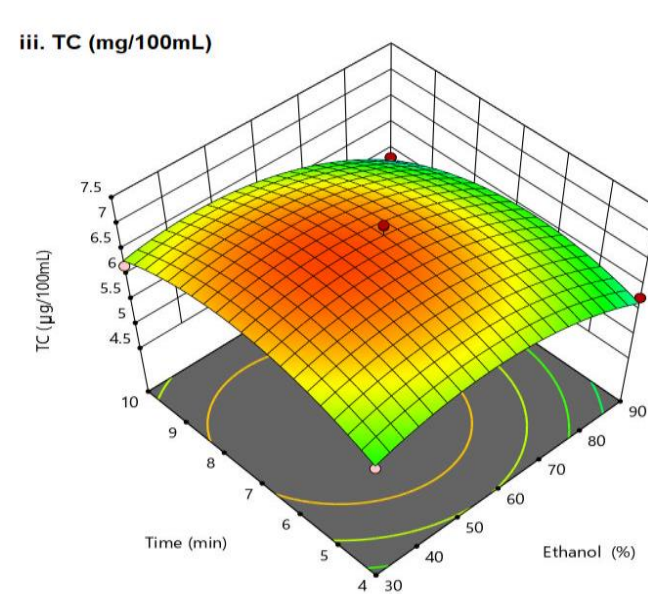

(a)

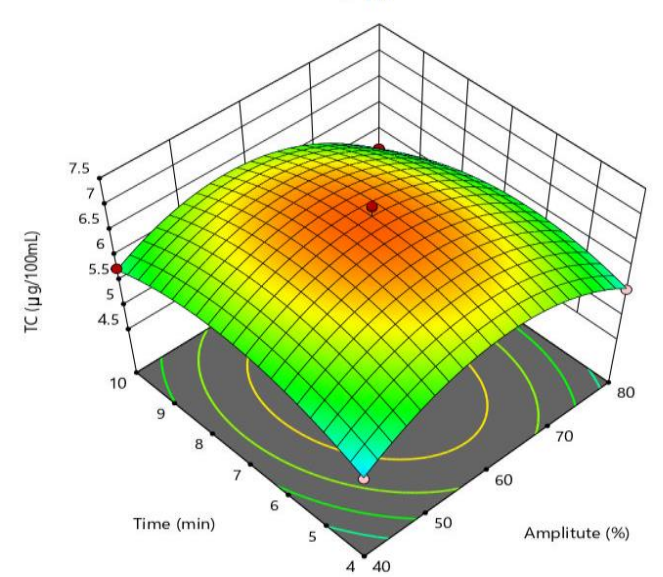

(b)

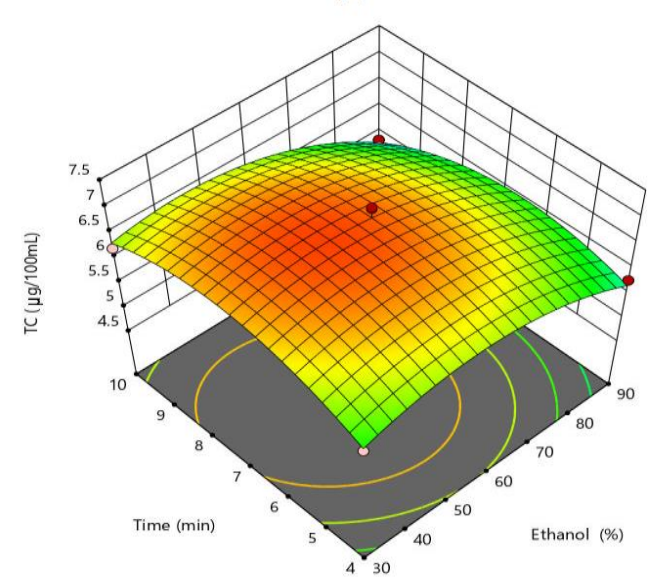

(c)

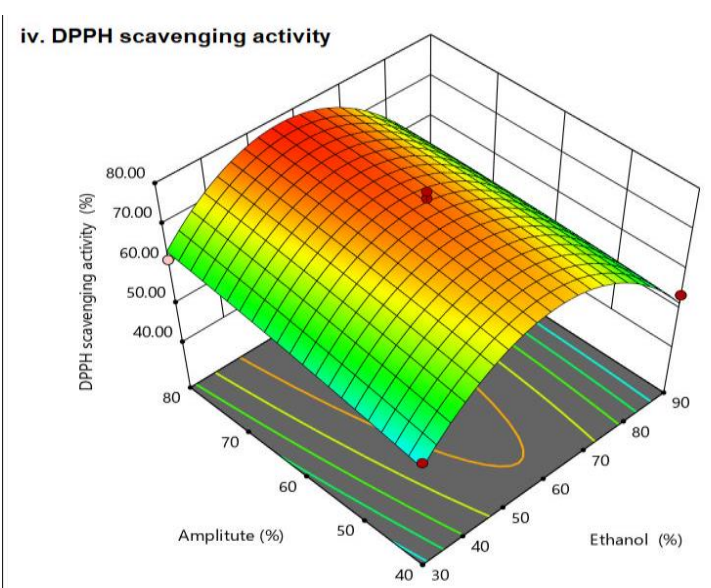

(a)

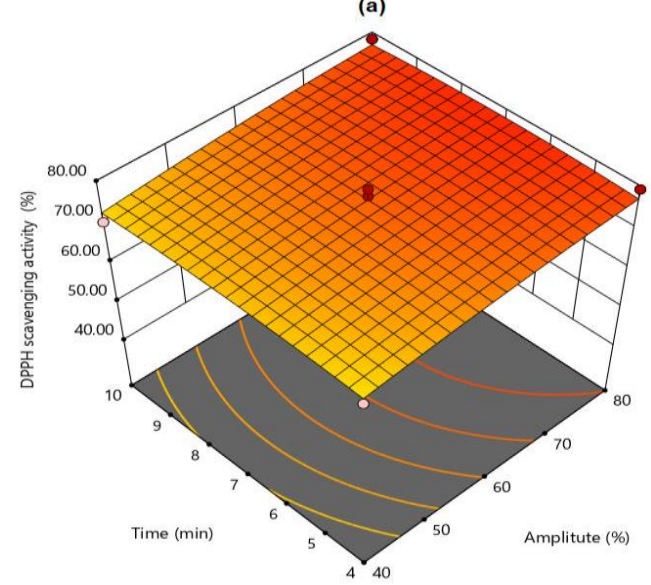

(b)

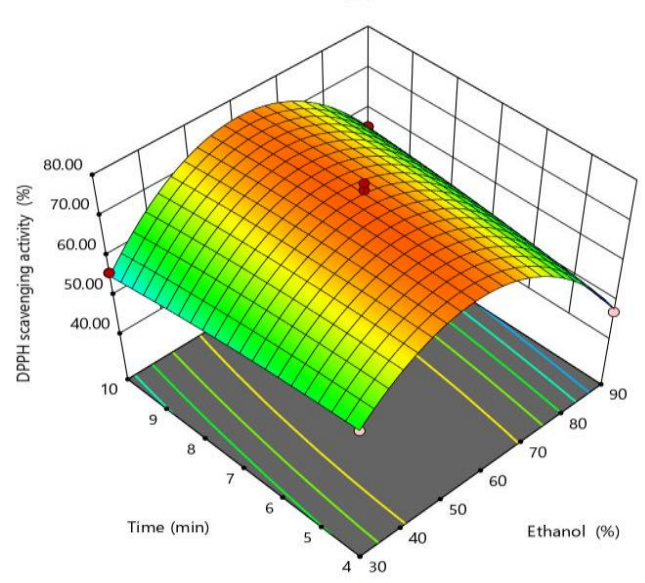

(c)

Figure 3. Response surfaces of TC and DPPH scavenging activity. 


\subsection{Optimization of operational variables.}

RSM optimization of variables has been carried out by numerical method. The ethanol concentration of $51.21 \%$, ultrasound amplitude of $51.45 \%$, and ultrasound treatment time of 6.11 minutes were found out to be optimized values of operational variables. Similar kinds of optimal values have been reported by Altemimi et al. (2016), Hossain et al. (2012), Khan et al. (2010), Prasad et al. (2011), and Wang et al. (2012). The optimized values of TPC, TF, TC, and DPPH scavenging activity were calculated at optimized values of variables and tabulated in Table 4. The desirability bar graph of variables and responses has shown in Figure 4. The overall desirability of the numerical optimization process was found out to be 0.843 , which is acceptable [86].

Table 4. RSM-optimized values of variables and responses.

\begin{tabular}{l|l} 
Parameters & RSM optimized values \\
\hline 1. Variables & 51.22 \\
\hline Ethanol concentration $(\%)$ & 51.45 \\
\hline Ultrasound amplitude $(\%)$ & 6.11 \\
\hline Ultrasound treatment time (minutes) & 70.79 \\
\hline 2. Responses & 45.85 \\
\hline TPC $(\mathrm{mg}$ gallic acid equivalent/100mL) & 6.75 \\
\hline TF $(\mathrm{mg}$ rutin acid equivalent $/ 100 \mathrm{~mL})$ & 74.40
\end{tabular}

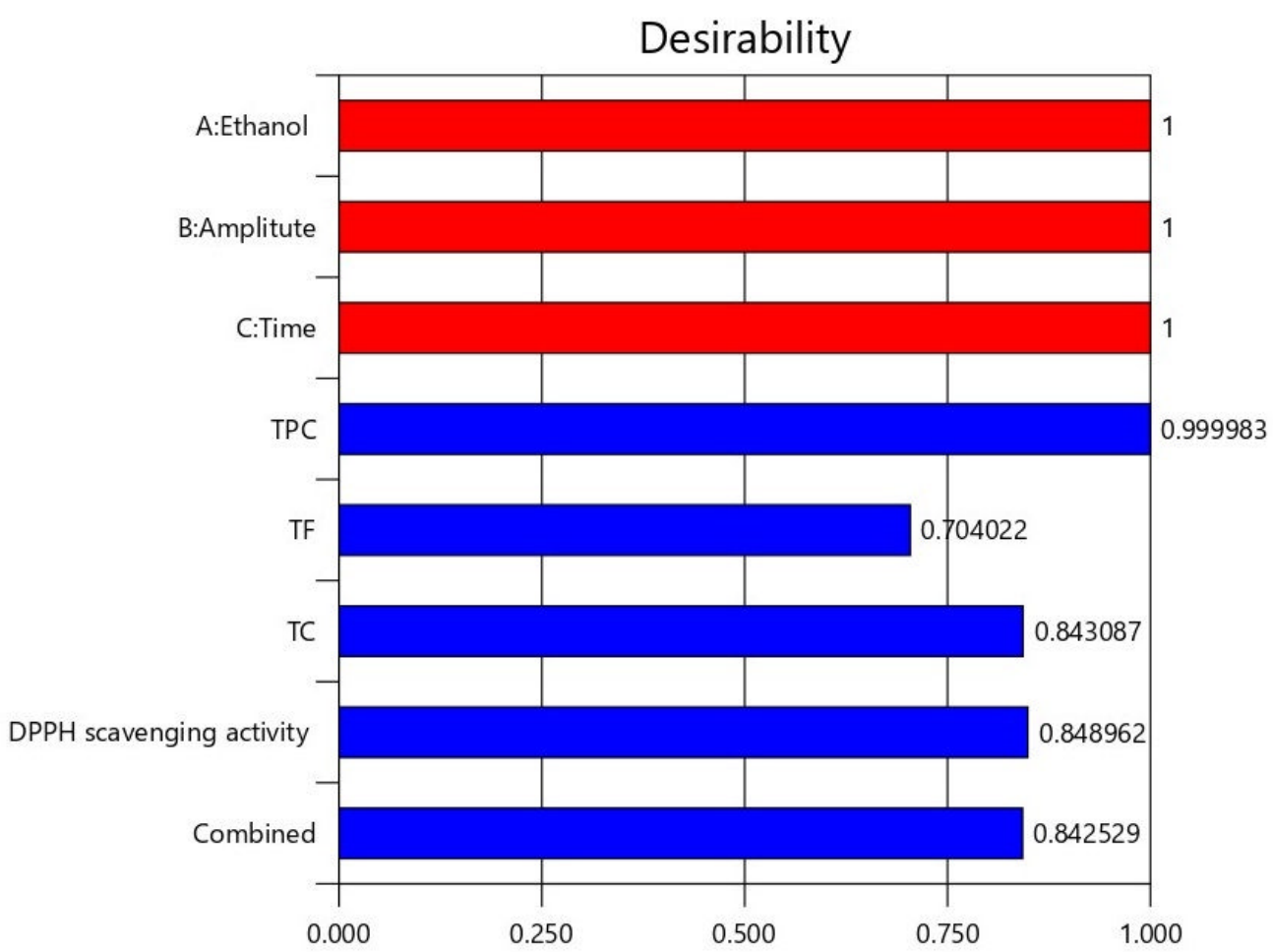

Figure 4. The desirability of variables and responses for the optimization of the extraction process.

\section{Conclusions}

The process of bale fruit juice extraction has shown the higher production of bael fruit pulp waste (BFPW) (37.33\%), and it was then recycled for the extraction of bioactive compounds to reduce solid food waste and, consequently, the environmental pollution through dumpings. The ultrasound-assisted extraction (UAE) was concluded to have the capability to increase the extraction efficiency of bioactive compounds than conventional solid-liquid 
extraction. RSM analysis of Box-Behnken design for the extraction process revealed that the ethanol concentration, ultrasound amplitude, and ultrasound treatment time were statistically significant for the process of extraction of bioactive compounds. Although, ultrasound treatment time had the least influence on the extraction of bioactive compounds than ethanol concentration and ultrasound amplitude. The values of RMSE and MAE were found to be within the acceptable limits and also validated the effectiveness of RSM for the process of ultrasound-assisted extraction of bioactive compounds from BFPW. The RSM analysis showed the ethanol concentration of $51.22 \%$, ultrasound amplitude of $51.45 \%$, and ultrasound treatment time of 6.11 minutes as an optimized value of operational variables for the extraction process of bioactive compounds such as polyphenols, flavonoids, carotenoids, etc. The present study revealed the richness of BFPW in terms of essential compounds that can be recovered efficiently by the ultrasound extraction method. Recovered or extracted compounds may be used either directly in liquid or as a lyophilized powder for its potential use in food and pharmaceutical medicines.

\section{Funding}

No funding was offered for this research.

\section{Acknowledgments}

There was no other kind of support for the acknowledgments.

\section{Conflicts of Interest}

The authors declare no conflict of interest.

\section{References}

1. Bag, S.; Srivastav, P.; Mishra, H. Desorption and adsorption characteristics of bael (Aegle marmelos) pulp and powder. Int Food Res 2009, 16, 561-569.

2. Bag, S.K.; Srivastav, P.P.; Mishra, H.N. Optimization of process parameters for foaming of bael (Aegle marmelos L.) fruit pulp. Food Bioprocess Tech 2011, 4, 1450-1458, https://doi.org/10.1007/s11947-0090243-6.

3. Sharma, G.N.; Dubey, S.K.; Sharma, P.; Sati, N. Medicinal values of bael (Aegle marmelos)(L.) Corr.: A review. Int J Curr Pharm Rev Res 2011, 2, 12-22.

4. Sawale, K.; Deshpande, H.; Kulkarni, D. Study of physico-chemical characteristics of bael (Aegle marmelos) fruit. Int J Pharmacogn Phytochem 2018, 7, 173-175.

5. Sonawane, A.; Pathak, S.S.; Pradhan, R.C. Physical, thermal, and mechanical properties of bael fruit. J Food Process Eng 2020, 43, https://doi.org/10.1111/jfpe.13393.

6. Jindal, M.; Kumar, V.; Rana, V.; Tiwary, A. Aegle marmelos fruit pectin for food and pharmaceuticals: Physico-chemical, rheological and functional performance. Carbohydr Polym 2013, 93, 386-394, https://doi.org/10.1016/j.carbpol.2012.12.012.

7. Baliga, M.S.; Bhat, H.P.; Joseph, N.; Fazal, F. Phytochemistry and medicinal uses of the bael fruit (Aegle marmelos Correa): A concise review. Food Res Int 2011, 44, 1768-1775, https://doi.org/10.1016/j.foodres.2011.02.008.

8. Roy, S.K.; Singh, R. Bael fruit (Aegle marmelos): A potential fruit for processing. Econ Bot 1979, 203-212, https://doi.org/10.1007/BF02858290.

9. Rakulini, R.; Kalaichelvi, S. A Review of Anti-Diarrheal Activity of Aegle marmelos. J Altern Complement Med 2019, 7, 1-10, https://doi.org/10.9734/jocamr/2019/v7i230095.

10. Bibak, B.; Shakeri, F.; Barreto, G.E.; Keshavarzi, Z.; Sathyapalan, T.; Sahebkar, A. A review of the pharmacological and therapeutic effects of auraptene. Biofactors 2019, 45, 867-879, https://doi.org/10.1002/biof.1550.

11. Kumar, K.; Yadav, A.N.; Kumar, V.; Vyas, P.; Dhaliwal, H.S. Food waste: a potential bioresource for extraction of nutraceuticals and bioactive compounds. Bioresour Bioprocess 2017, 4, 18, https://doi.org/10.1186/s40643-017-0148-6. 
12. Sagar, N.A.; Pareek, S.; Sharma, S.; Yahia, E.M.; Lobo, M.G. Fruit and vegetable waste: Bioactive compounds, their extraction, and possible utilization. Compr Rev Food Sci Food Saf 2018, 17, 512-531, https://doi.org/10.1111/1541-4337.12330.

13. Gan, C.-Y.; Latiff, A.A. Optimisation of the solvent extraction of bioactive compounds from Parkia speciosa pod using response surface methodology. Food Chem 2011, 124, 1277-1283, https://doi.org/10.1016/j.foodchem.2010.07.074.

14. Angiolillo, L.; Del Nobile, M.A.; Conte, A. The extraction of bioactive compounds from food residues using microwaves. Curr Opin Food Sci 2015, 5, 93-98, https://doi.org/10.1016/j.cofs.2015.10.001.

15. Kibler, K.M.; Reinhart, D.; Hawkins, C.; Motlagh, A.M.; Wright, J. Food waste and the food-energy-water nexus: a review of food waste management alternatives. $J$ Waste Manag 2018, 74, 52-62, https://doi.org/10.1016/j.wasman.2018.01.014.

16. Kaur, A.; Kalia, M. Physico chemical analysis of bael (Aegle Marmelos) fruit pulp, seed and pericarp. Chem Sci Rev Lett 2017, 6, 1213-1218.

17. Bhattacherjee, A.; Dikshit, A.; Pandey, D.; Tandon, D. High performance liquid chromatographic determination of marmelosin and psoralen in bael (Aegle marmelos (L.) Correa) fruit. J Food Sci Tech 2015, 52, 597-600, https://doi.org/10.1007/s13197-013-1015-x.

18. Sonawane, A.; Pathak, S.; Pradhan, R.C. Effect of Processing Temperature on Dynamic Rheological Properties and Color Degradation Kinetics of Bael Fruit Pulp. J Sci Food Agric 2020, https://doi.org/10.1002/jsfa.10612.

19. Sornsomboonsuk, S.; Junyusen, T.; Chatchavanthatri, N.; Moolkaew, P.; Pamkhuntod, N. Evaluation of Physicochemical Properties of Spray Dried Bael Fruit Powder During Storage. Int J Food Eng 2019, 5, 209213.

20. Kaur, A.; Kochhar, A.; Boora, R.; Javed, M. Incorporation of Bael (aegle marmelos L.) Pulp and Stevia (stevia rebaudiana) Powder in Value Added Sweet Products. Curr J Appl Sci Technol 2019, 38, 1-10, https://doi.org/10.9734/cjast/2019/v38i230356.

21. Bhardwaj, R.; Nandal, U. Nutritional and therapeutic potential of bael (Aegle Marmelos Corr.) fruit juice: a review. Nutr Food Sci 2015, 45, 895-919, https://doi.org/10.1108/NFS-05-2015-0058.

22. Chauthe, S.K.; Sharma, R.J.; Aqil, F.; Gupta, R.C.; Singh, I.P. Quantitative NMR: an applicable method for quantitative analysis of medicinal plant extracts and herbal products. Phytochem Anal 2012, 23, 689-696, https://doi.org/10.1002/pca.2375.

23. Gurjar, P.S.; Lal, N.; Gupta, A.K.; Marboh, E.S. A Review on medicinal values and commercial utility of Bael. International Journal of Life-Scienes Scientific Research 2015, 1, 5-7.

24. Stalikas, C.D. Extraction, separation, and detection methods for phenolic acids and flavonoids. J Sep Sci 2007, 30, 3268-3295, https://doi.org/10.1002/jssc.200700261.

25. Zhang, H.-F.; Yang, X.-H.; Zhao, L.-D.; Wang, Y. Ultrasonic-assisted extraction of epimedin C from fresh leaves of Epimedium and extraction mechanism. Innov Food Sci Emerg Techno 2009, 10, 54-60, https://doi.org/10.1016/j.ifset.2008.09.007.

26. Hayat, K.; Hussain, S.; Abbas, S.; Farooq, U.; Ding, B.; Xia, S.; Jia, C.; Zhang, X.; Xia, W. Optimized microwave-assisted extraction of phenolic acids from citrus mandarin peels and evaluation of antioxidant activity in vitro. Sep Purif Technol 2009, 70, 63-70, https://doi.org/10.1016/j.seppur.2009.08.012.

27. Oliveira, A.L.; Kamimura, E.S.; Rabi, J.A. Response surface analysis of extract yield and flavour intensity of Brazilian cherry (Eugenia uniflora L.) obtained by supercritical carbon dioxide extraction. Innov Food Sci Emerg Techno 2009, 10, 189-194, https://doi.org/10.1016/j.ifset.2008.11.002.

28. Wang, L.; Yang, B.; Du, X.; Yi, C. Optimisation of supercritical fluid extraction of flavonoids from Pueraria lobata. Food Chem 2008, 108, 737-741, https://doi.org/10.1016/j.foodchem.2007.11.031.

29. Maran, J.P.; Sivakumar, V.; Thirugnanasambandham, K.; Sridhar, R. Extraction of natural anthocyanin and colors from pulp of jamun fruit. J Food Sci Tech 2015, 52, 3617-3626, https://doi.org/10.1007/s13197-0141429-0.

30. Xu, Y.; Zhang, R.; Fu, H. Studies on the optimal process to extract flavonoids from red-raspberry fruits. Nature and Science 2005, 3, 43-46.

31. Khan, M.K.; Abert-Vian, M.; Fabiano-Tixier, A.-S.; Dangles, O.; Chemat, F. Ultrasound-assisted extraction of polyphenols (flavanone glycosides) from orange (Citrus sinensis L.) peel. Food Chem 2010, 119, 851858, https://doi.org/10.1016/j.foodchem.2009.08.046.

32. Munir, M.; Kheirkhah, H.; Baroutian, S.; Quek, S.Y.; Young, B.R. Subcritical water extraction of bioactive compounds from waste onion skin. J Clean Prod 2018, 183, 487-494, https://doi.org/10.1016/j.jclepro.2018.02.166.

33. Wen, C.; Zhang, J.; Zhang, H.; Dzah, C.S.; Zandile, M.; Duan, Y.; Ma, H.; Luo, X. Advances in ultrasound assisted extraction of bioactive compounds from cash crops-A review. Ultrason Sonochem 2018, 48, 538549, https://doi.org/10.1016/j.ultsonch.2018.07.018.

34. Santos, M.P.; Souza, M.C.; Sumere, B.R.; da Silva, L.C.; Cunha, D.T.; Bezerra, R.M.N.; Rostagno, M.A. Extraction of bioactive compounds from pomegranate peel (Punica granatum L.) with pressurized liquids assisted by ultrasound combined with an expansion gas. Ultrason Sonochem 2019, 54, 11-17, https://doi.org/10.1016/j.ultsonch.2019.02.021. 
35. Vinatoru, M. An overview of the ultrasonically assisted extraction of bioactive principles from herbs. Ultrason Sonochem 2001, 8, 303-313, https://doi.org/10.1016/S1350-4177(01)00071-2.

36. Wang, C.; Zuo, Y. Ultrasound-assisted hydrolysis and gas chromatography-mass spectrometric determination of phenolic compounds in cranberry products. Food Chem 2011, 128, 562-568, https://doi.org/10.1016/j.foodchem.2011.03.066.

37. Albu, S.; Joyce, E.; Paniwnyk, L.; Lorimer, J.; Mason, T.J. Potential for the use of ultrasound in the extraction of antioxidants from Rosmarinus officinalis for the food and pharmaceutical industry. Ultrason Sonochem 2004, 11, 261-265, https://doi.org/10.1016/j.ultsonch.2004.01.015.

38. Goula, A.M.; Ververi, M.; Adamopoulou, A.; Kaderides, K. Green ultrasound-assisted extraction of carotenoids from pomegranate wastes using vegetable oils. Ultrason Sonochem 2017, 34, 821-830, https://doi.org/10.1016/j.ultsonch.2016.07.022.

39. Altemimi, A.; Watson, D.G.; Choudhary, R.; Dasari, M.R.; Lightfoot, D.A. Ultrasound assisted extraction of phenolic compounds from peaches and pumpkins. PloS one 2016, 11, https://doi.org/10.1371/journal.pone.0148758.

40. Celli, G.B.; Ghanem, A.; Brooks, M.S.-L. Optimization of ultrasound-assisted extraction of anthocyanins from haskap berries (Lonicera caerulea L.) using Response Surface Methodology. Ultrason Sonochem 2015, 27, 449-455, https://doi.org/10.1016/j.ultsonch.2015.06.014.

41. Altemimi, A.; Choudhary, R.; Watson, D.G.; Lightfoot, D.A. Effects of ultrasonic treatments on the polyphenol and antioxidant content of spinach extracts. Ultrason Sonochem 2015, 24, 247-255, https://doi.org/10.1016/j.ultsonch.2014.10.023.

42. Garcia-Castello, E.M.; Rodriguez-Lopez, A.D.; Mayor, L.; Ballesteros, R.; Conidi, C.; Cassano, A. Optimization of conventional and ultrasound assisted extraction of flavonoids from grapefruit (Citrus paradisi L.) solid wastes. LWT-Food Sci Technol 2015, 64, 1114-1122, https://doi.org/10.1016/j.lwt.2015.07.024.

43. Almahy, H.; Ali, M.; Band, A. Extraction of Carotenoids as natural dyes from the Daucus carota Linn (carrot) using ulturasound in Kingdoum of Saudi Arabia. Res J Chem Sci 2013, 3, 63-66.

44. Hossain, M.B.; Brunton, N.P.; Patras, A.; Tiwari, B.; O’donnell, C.; Martin-Diana, A.B.; Barry-Ryan, C. Optimization of ultrasound assisted extraction of antioxidant compounds from marjoram (Origanum majorana L.) using response surface methodology. Ultrason Sonochem 2012, 19, 582-590, https://doi.org/10.1016/j.ultsonch.2011.11.001.

45. Wang, J.; Zhao, Y.-M.; Guo, C.-Y.; Zhang, S.-M.; Liu, C.-L.; Zhang, D.-S.; Bai, X.-M. Ultrasound-assisted extraction of total flavonoids from Inula helenium. Pharmacogn Mag 2012, 8, 166-170, https://doi.org/10.4103/0973-1296.96581.

46. Prasad, K.N.; Hassan, F.A.; Yang, B.; Kong, K.W.; Ramanan, R.N.; Azlan, A.; Ismail, A. Response surface optimisation for the extraction of phenolic compounds and antioxidant capacities of underutilised Mangifera pajang Kosterm. peels. Food Chem 2011, 128, 1121-1127, https://doi.org/10.1016/j.foodchem.2011.03.105.

47. Zhang, G.; He, L.; Hu, M. Optimized ultrasonic-assisted extraction of flavonoids from Prunella vulgaris L. and evaluation of antioxidant activities in vitro. Innov Food Sci Emerg Techno 2011, 12, 18-25, https://doi.org/10.1016/j.ifset.2010.12.003.

48. Huang, W.; Xue, A.; Niu, H.; Jia, Z.; Wang, J. Optimised ultrasonic-assisted extraction of flavonoids from Folium eucommiae and evaluation of antioxidant activity in multi-test systems in vitro. Food Chem 2009, 114, 1147-1154, https://doi.org/10.1016/j.foodchem.2008.10.079.

49. Ma, Y.Q.; Chen, J.C.; Liu, D.H.; Ye, X.Q. Effect of ultrasonic treatment on the total phenolic and antioxidant activity of extracts from citrus peel. J Food Sci 2008, 73, T115-T120, https://doi.org/10.1111/j.17503841.2008.00908.X.

50. Ma, Y.-Q.; Ye, X.-Q.; Fang, Z.-X.; Chen, J.-C.; Xu, G.-H.; Liu, D.-H. Phenolic compounds and antioxidant activity of extracts from ultrasonic treatment of Satsuma mandarin (Citrus unshiu Marc.) peels. J Agric Food Chem 2008, 56, 5682-5690, https://doi.org/10.1021/jf072474o.

51. Sharayei, P.; Azarpazhooh, E.; Zomorodi, S.; Ramaswamy, H.S. Ultrasound assisted extraction of bioactive compounds from pomegranate (Punica granatum L.) peel. LWT-Food Sci Technol 2019, 101, 342-350, https://doi.org/10.1016/j.lwt.2018.11.031.

52. Manzoor, M.F.; Zeng, X.-A.; Rahaman, A.; Siddeeg, A.; Aadil, R.M.; Ahmed, Z.; Li, J.; Niu, D. Combined impact of pulsed electric field and ultrasound on bioactive compounds and FT-IR analysis of almond extract. J Food Sci Tech 2019, 56, 2355-2364, https://doi.org/10.1007/s13197-019-03627-7.

53. Hassan, F.A.; Ismail, A.; Hamid, A.A.; Azlan, A.; Al-sheraji, S.H. Characterisation of fibre-rich powder and antioxidant capacity of Mangifera pajang K. fruit peels. Food Chem 2011, 126, 283-288, https://doi.org/10.1016/j.foodchem.2010.11.019.

54. Ibrahim, M.; Prasad, K.N.; Hamid, A. Physiochemical composition and antioxidant activities of underutilized Mangifera pajang fruit. Afr J Biotechnol 2010, 9, 4392-4327.

55. Khoo, H.-E.; Prasad, K.N.; Ismail, A.; Mohd-Esa, N. Carotenoids from Mangifera pajang and their antioxidant capacity. Molecules 2010, 15, 6699-6712, https://doi.org/10.3390/molecules15106699.

56. Boadi, W.Y.; Iyere, P.A.; Adunyah, S.E. Effect of quercetin and genistein on copper-and iron-induced lipid peroxidation in methyl linolenate. J Appl Toxicol 2003, 23, 363-369, https://doi.org/10.1002/jat.933. 
57. Terao, J.; Piskula, M.; Yao, Q. Protective effect of epicatechin, epicatechin gallate, and quercetin on lipid peroxidation in phospholipid bilayers. Arch Biochem Biophys 1994, 308, 278-284, https://doi.org/10.1006/abbi.1994.1039.

58. Flagg, E.W.; Coates, R.J.; Greenberg, R.S. Epidemiologic studies of antioxidants and cancer in humans. J Am Coll Nutr 1995, 14, 419-427, https://doi.org/10.1080/07315724.1995.10718532.

59. Horwitz, W.; Chichilo, P.; Reynolds, H. Official Methods of Analysis of the Association of Official Agricultural Chemists (AOAC). AOAC International: Gaithersburg, MD, USA 2012.

60. Vivek, K.; Mishra, S.; Pradhan, R.C. Optimization of ultrasound-assisted enzymatic extraction of Sohiong (Prunus nepalensis) juice. J Food Process Eng 2019, 42, https://doi.org/10.1111/jfpe.12948.

61. Singh, A.; Kumar, S.; Sharma, H. Effect of enzymatic hydrolysis on the juice yield from bael fruit (Aegle marmelos Correa) pulp. Am J Food Technol 2012, 7, 62-72, https://doi.org/10.3923/ajft.2012.62.72.

62. Singleton, V.L.; Rossi, J.A. Colorimetry of total phenolics with phosphomolybdic-phosphotungstic acid reagents. Am J Enol Viticult 1965, 16, 144-158,

63. Woisky, R.G.; Salatino, A. Analysis of propolis: some parameters and procedures for chemical quality control. J Apic Res 1998, 37, 99-105, https://doi.org/10.1080/00218839.1998.11100961.

64. Hess, D.; Keller, H.; Oberlin, B.; Bonfanti, R.; Schüep, W. Simultaneous determination of retinol, tocopherols, carotenes and lycopene in plasma by means of high-performance liquid chromatography on reversed phase. Int J Vitam Nutr Res 1991, 61, 232-238.

65. Liu, W.; Fu, Y.-J.; Zu, Y.-G.; Tong, M.-H.; Wu, N.; Liu, X.-L.; Zhang, S. Supercritical carbon dioxide extraction of seed oil from Opuntia dillenii Haw. and its antioxidant activity. Food Chem 2009, 114, 334339, https://doi.org/10.1016/j.foodchem.2008.09.049.

66. Botinestean, C.; Hossain, M.; Mullen, A.M.; Auty, M.A.; Kerry, J.P.; Hamill, R.M. Optimization of textural and technological parameters using response surface methodology for the development of beef products for older consumers. J Texture Stud 2020, 51, 263-275, https://doi.org/10.1111/jtxs.12467.

67. Pongsumpun, P.; Iwamoto, S.; Siripatrawan, U. Response surface methodology for optimization of cinnamon essential oil nanoemulsion with improved stability and antifungal activity. Ultrason Sonochem 2020, 60, https://doi.org/10.1016/j.ultsonch.2019.05.021.

68. Razmi-Rad, E.; Ghanbarzadeh, B.; Mousavi, S.; Emam-Djomeh, Z.; Khazaei, J. Prediction of rheological properties of Iranian bread dough from chemical composition of wheat flour by using artificial neural networks. J Food Eng 2007, 81, 728-734, https://doi.org/10.1016/j.jfoodeng.2007.01.009.

69. Youssefi, S.; Emam-Djomeh, Z.; Mousavi, S. Comparison of artificial neural network (ANN) and response surface methodology (RSM) in the prediction of quality parameters of spray-dried pomegranate juice. Dry Technol 2009, 27, 910-917, https://doi.org/10.1080/07373930902988247.

70. Shrestha, G.L. Processing of wild Bael fruit for rural employment and income generation. ITDG Food Chain 2000, 27.

71. Stephen, A.M.; Cummings, J. Water-holding by dietary fibre in vitro and its relationship to faecal output in man. Gut 1979, 20, 722-729, http://dx.doi.org/10.1136/gut.20.8.722.

72. Chemat, S.; Lagha, A.; AitAmar, H.; Bartels, P.V.; Chemat, F. Comparison of conventional and ultrasoundassisted extraction of carvone and limonene from caraway seeds. Flavour Frag J 2004, 19, 188-195, https://doi.org/10.1002/ffj.1339.

73. Hromádková, Z.; Košt’Álová, Z.; Ebringerová, A. Comparison of conventional and ultrasound-assisted extraction of phenolics-rich heteroxylans from wheat bran. Ultrason Sonochem 2008, 15, 1062-1068, https://doi.org/10.1016/j.ultsonch.2008.04.008.

74. Cacace, S.; Schröder, G.; Wehinger, E.; Strack, D.; Schmidt, J.; Schröder, J. A flavonol O-methyltransferase from Catharanthus roseus performing two sequential methylations. Phytochemistry 2003, 62, 127-137, https://doi.org/10.1016/S0031-9422(02)00483-1.

75. Durling, N.E.; Catchpole, O.J.; Grey, J.B.; Webby, R.F.; Mitchell, K.A.; Foo, L.Y.; Perry, N.B. Extraction of phenolics and essential oil from dried sage (Salvia officinalis) using ethanol-water mixtures. Food Chem 2007, 101, 1417-1424, https://doi.org/10.1016/j.foodchem.2006.03.050.

76. Pompeu, D.; Silva, E.; Rogez, H. Optimisation of the solvent extraction of phenolic antioxidants from fruits of Euterpe oleracea using Response Surface Methodology. Bioresour Technol 2009, 100, 6076-6082, https://doi.org/10.1016/j.biortech.2009.03.083.

77. Raso, J.; Manas, P.; Pagan, R.; Sala, F.J. Influence of different factors on the output power transferred into medium by ultrasound. Ultrason Sonochem 1999, 5, 157-162, https://doi.org/10.1016/S13504177(98)00042-X.

78. Vilkhu, K.; Mawson, R.; Simons, L.; Bates, D. Applications and opportunities for ultrasound assisted extraction in the food industry-A review. Innov Food Sci Emerg Techno 2008, 9, 161-169, https://doi.org/10.1016/j.ifset.2007.04.014.

79. Boonkird, S.; Phisalaphong, C.; Phisalaphong, M. Ultrasound-assisted extraction of capsaicinoids from Capsicum frutescens on a lab-and pilot-plant scale. Ultrason Sonochem 2008, 15, 1075-1079, https://doi.org/10.1016/j.ultsonch.2008.04.010.

80. Yang, Y.; Zhang, F. Ultrasound-assisted extraction of rutin and quercetin from Euonymus alatus (Thunb.) Sieb. Ultrason Sonochem 2008, 15, 308-313, https://doi.org/10.1016/j.ultsonch.2007.05.001. 
81. Favre, L.C.; Rolandelli, G.; Mshicileli, N.; Vhangani, L.N.; dos Santos Ferreira, C.; van Wyk, J.; del Pilar Buera, M. Antioxidant and anti-glycation potential of green pepper (Piper nigrum): Optimization of $\beta$ cyclodextrin-based extraction by response surface methodology. Food Chem 2020, 316, https://doi.org/10.1016/j.foodchem.2020.126280.

82. Joglekar, A.M.; May, A.T.; Graf, E.; Saguy, I. Product excellence through experimental design. Food product and development: From concept to the marketplace. 1987; pp. 211.

83. Chegini, G.; Khazaei, J.; Ghobadian, B.; Goudarzi, A. Prediction of process and product parameters in an orange juice spray dryer using artificial neural networks. $J$ Food Eng 2008, 84, 534-543, https://doi.org/10.1016/j.jfoodeng.2007.06.007.

84. Espinosa-Andrews, H.; Páez-Hernández, G. Optimization of ultrasonication curcumin-hydroxylated lecithin nanoemulsions using response surface methodology. J Food Sci Tech 2020, 57, 549-556, https://doi.org/10.1007/s13197-019-04086-w.

85. Amendola, D.; De Faveri, D.M.; Spigno, G. Grape marc phenolics: Extraction kinetics, quality and stability of extracts. J Food Eng 2010, 97, 384-392, https://doi.org/10.1016/j.jfoodeng.2009.10.033.

86. Bose, P.; Pradhan, D.; Sonawane, A.; Pathak, S.S.; Anupriya, S.; Pradhan, R.C. Optimization of hot air and microwave pretreatment for enhancing the mechanical expression yield of Simarouba glauca oil. J Agric Food Res 2020, 2, https://doi.org/10.1016/j.jafr.2020.100024. 